Chapter 2

\title{
Powder Preparation, Properties and Industrial Applications of Hexagonal Boron Nitride
}

\author{
Burcu Ertuğ \\ Additional information is available at the end of the chapter \\ http://dx.doi.org/10.5772/53325
}

\section{Introduction}

Boron nitride was first prepared in 1840's by an English chemist, W.H.Balmain, by using molten boric acid and potassium cyanide, but unfortunately this new compound was unstable and required many attempts to obtain a stable boron nitride. For nearly a hundred years studies on boron nitride remained in laboratory scale because of the technical difficulties of different production techniques and high cost of the material which is obtained with these synthetic methods but in 1950's Carborundum and Union Carbide companies managed to prepare boron nitride powder on an industrial scale and fabricated shaped parts of boron nitride for commercial applications with sophisticated hot pressing techniques [1].

\section{Synthesis of boron nitride}

Several methods have been studied for the synthesis of boron nitride. A chart prepared by D.Fister showing the possible routes to produce boron nitride is given in Figure 1.

A partial list showing generalized methods to produce hexagonal boron nitride is also given here :

1. Direct nitridation of boron according to

$2 \mathrm{~B}+\mathrm{N}_{2}=2 \mathrm{BN}$

reaction. This method is limited since pure boron is an expensive element and nitridation of the element is not homogeneous even at high temperatures [2]. 
2. Nitridation of an oxygen containing boron compound with a nitrogen containing compound such as ammonia or ammonium compound. Borates such as boric acid $\left(\mathrm{H}_{3} \mathrm{BO}_{3}\right)$ or borax $\left(\mathrm{Na}_{2} \mathrm{~B}_{4} \mathrm{O}_{7}\right)$ are heated in the presence of a nitrogen-containing compound such as ammonia or urea $\left(\left(\mathrm{NH}_{2}\right)_{2} \mathrm{CO}\right)$ to form a B-N bond. Such reactions are usually carried out at temperatures $800-1200^{\circ} \mathrm{C}$ and due to the low melting of boron compounds, inert fillers such as tri-calcium phosphate are used. Carbon addition might be required to tide the excess oxygen. Since reactants and fillers create a large volume, the flow through the porous media is dominant in synthesis. Ingles and Popper tried re-nitrided $\mathrm{BN}$ as solid filler to eliminate the further processes to purify the powder but obtained lower yields probably due to the fact that $\mathrm{BN}$ filler is not wetted by boric oxide $[2,3]$.

Although this route can yield cheap product, the reaction kinetics and the state-ofart is not given in the scientific literature. Ingles and Popper employed this reaction; however, together with a complicated and excessive flow chart. Kuhn et. al, also employed this reaction in an arc plasma reactor. Their work consisted of a vaporphase reaction between boric oxide and ammonia at $800-2400^{\circ} \mathrm{C}$. The product was ultrafine boron nitride powder having a thickness in the c-direction of between $20-50 \mathrm{~A}^{\mathrm{o}}$. It was noted that the boric oxide vapor should not be allowed to condense into large particles susceptible to boron nitride barrier film formation and that the ammonia should not be allowed to fully dissociate before contacting the boric oxide vapor [2].

3. Reacting alkali metal borides or alkaline earth metal borides with silicon and/or aluminum or their alloys while mixtures of an alkali metal oxide and alkali metal borates or boron trioxide are present in a nitrogen containing atmosphere at a temperature between $200-1200^{\circ} \mathrm{C}$. The product is leached after the reaction to remove the water soluble alkali metal salts. This method however, requires the preparation of starting materials and a tedious leaching step in order to remove the difficultly soluble trimetal hydroxide impurities. Knorre et al., patented a process which employs such a reaction [2].

4. Through reactions involving the formation of elemento-organic BN compounds as intermediate-reaction products, the carbothermic decomposition of which would yield $\mathrm{BN}$. By this method, high purity BN powder at temperatures below those of conventional techniques has been obtained at laboratory scale. Such elemento-organic BN compounds could be boranes and borazines. Among boranes, both amine boranes and amino boranes are potential candidates. Amine boranes are compounds of amines and the borane unit or substituted boranes.These compounds can be derived from halides through direct combination of reactants or by indirect elmination and displacement reactions.Monomeric aminoboranes are characterized by a structure in which boron and nitrogen are coordinately unsaturated. The disadvantage is that all of these starting materials are oxygen and moisture sensitive and best prepared prior to being used [2].

5. Pressure pyrolysis of borazine $\left(\mathrm{B}_{3} \mathrm{~N}_{3} \mathrm{H}_{6}\right)$ can also yield to $\mathrm{BN}$, namely in amorphous form. The yield in such a route is reported to be as high as $60 \%$ by Hirano et al. [2]. 


\section{Properties of hexagonal boron nitride}

Key boron nitride properties are high thermal conductivity, low thermal expansion, good thermal shock resistance, high electrical resistance, low dielectric constant and loss tangent, microwave transparency, non toxicity, easily machinability- non-abrasive and lubricious, chemical inertness, non-wetting by most molten metals [4].

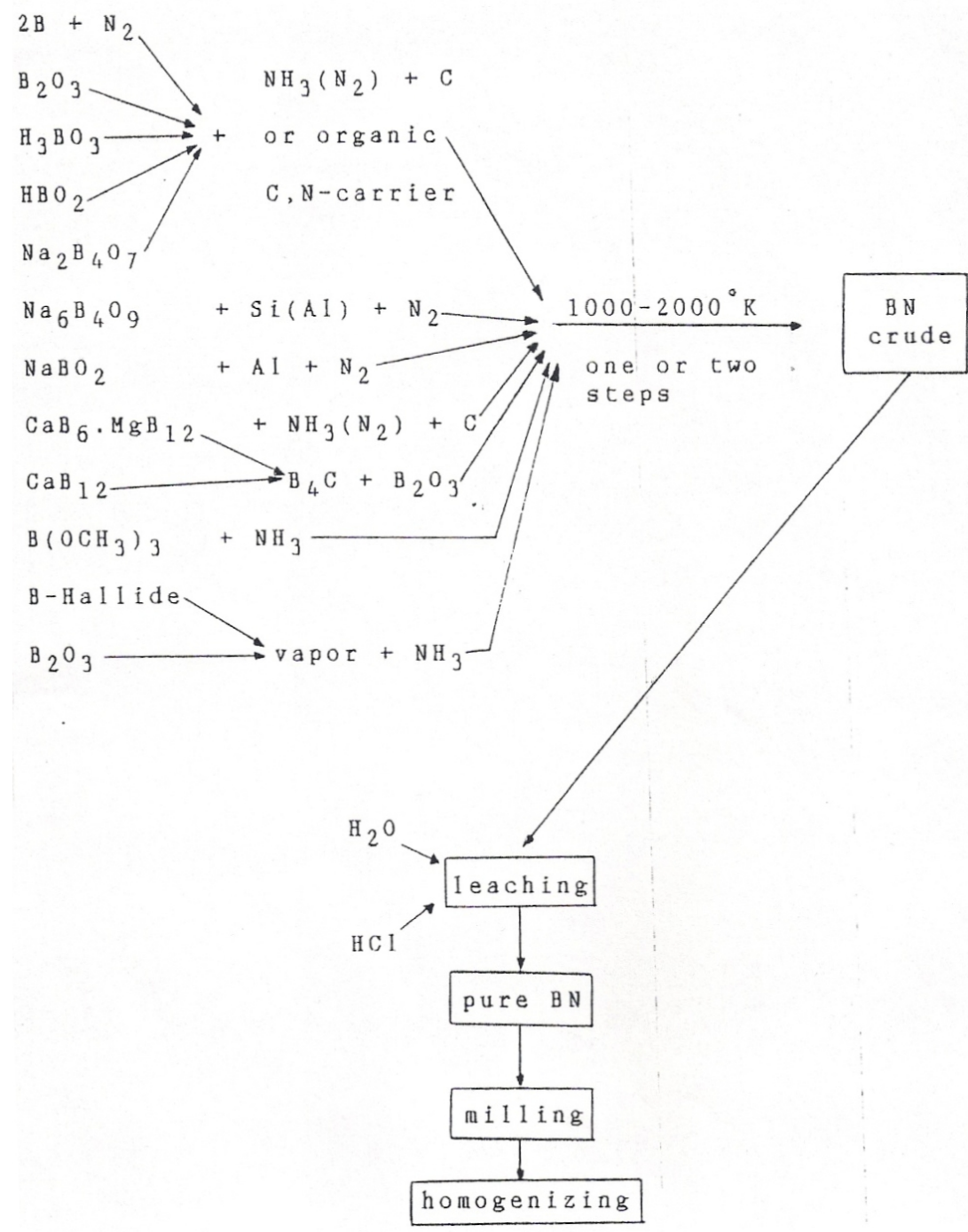

Figure 1. Possible routes to produce boron nitride [2]. 
Hexagonal boron nitride is being used increasingly because of its unique combination of properties which include a low density ( $2.27 \mathrm{~g} . \mathrm{cm}^{-3}$ theoretical density), high temperature stability (melting point near $2600^{\circ} \mathrm{C}$ ), chemical inertness (corrosion resistance against acids and molten metals), stability in air up to $1000^{\circ} \mathrm{C}$ (in argon gas atmosphere up to $2200^{\circ} \mathrm{C}$ and in nitrogen up to $2400^{\circ} \mathrm{C}$ ), stability to thermal shock, easy workability of hot-pressed shapes, excellent electrical insulating character as well as very high thermal conductivity. As a thermal conductor, $\mathrm{BN}$ ranks with stainless steel at cryogenic temperatures and with beryllium oxide, $\mathrm{BeO}$, at elevated conditions; above $700^{\circ} \mathrm{C}$, the thermal conductivity of hexagonal boron nitride exceeds that of toxic $\mathrm{BeO}$ [5].

Of particular interest are its good dielectric properties (dielectric constant is 4, i.e half of that of $\alpha-\mathrm{Al}_{2} \mathrm{O}_{3}$ ), also high dielectric strength and its ability to lubricate over a wide range of temperatures. Its small coefficient of friction is retained up to $900^{\circ} \mathrm{C}$, whereas other solid lubricants like graphite and molybdenum disulphide are burnt away at lower temperatures. Because of its high temperature stability and inertness against carbon and carbon monoxide up to $1800^{\circ} \mathrm{C}$ it is as a refractory ceramic superior to the nitride ceramics $\mathrm{Si}_{3} \mathrm{~N}_{4}$ and $\mathrm{AlN}$ and the oxide ceramics $\mathrm{MgO}, \mathrm{CaO}, \mathrm{ZrO}_{2}$. Due to its non-wetting properties it is stable to attack by molten glass, molten silicon, boron, nonoxidizing slags, molten salts (borax, cryolite) and reactive metal melts (e.g $\mathrm{Al}, \mathrm{Fe}, \mathrm{Cu}, \mathrm{Zn}$ ). Because of its poor sinterability, dense shapes of hexagonal boron nitride are obtained almost exclusively by hot-pressing [5].

It must be recognized that the most chemical and physical properties of axial hot-pressed BN shapes depend on the nature and the amount of additives used for densification (up to $6 \mathrm{wt}$. $\%$ of $\mathrm{B}_{2} \mathrm{O}_{3}$, metal borates or $\mathrm{SiO}_{2}$ ). Further some thermal (coefficient of expansion, thermal conductivity) and mechanical (flexural strength, Young's modulus) property values vary according to the direction of hot-pressing, $\mathrm{BN}$ being similar to graphite in respect of anisotropy. By hot-pressing isostatic of canned BN-powder, theoretically dense and pure hexagonal boron nitride shapes without texture (isotropic) and with improved properties can nowadays be obtained [5].

\section{Applications of boron nitride}

As can be seen from Figure 2, hexagonal boron nitride has established itself in the various field of chemistry, metallurgy, high temperature technology, electrotechnology and electronics [5].

Typical boron nitride uses are electronic parts (heat sinks, substrates, coil forms, prototypes), boron doping wafers in silicon semiconductor processing, vacuum melting crucibles, CVD crucibles, microcircuit packaging, sputtering targets, high precision sealing, brazing and metallizing fixtures, microwave tubes, horiziontal caster break rings, low friction seals, plasma arc insulators, high temperature furnace fixtures and supports [4].

In the following, a few examples of the uses for hexagonal boron nitride hot-pressed shapes are described in detail. 
Hexagonal boron nitride powder

* Solid lubricant for high temperature bearings

* Mould release agent for die casting of glass and metals

* Active filler for rubber, resins and plastics

* Additive to oils and high-temperature grease

* Ultrahigh-pressure transmitting agent

* Coatings for evaporation plants

* Coating for graphite hot pressing moulds

* Embedding medium for heating wires

* Boron source for preparation of $\mathrm{c}-\mathrm{BN}$ and ceramic composites

Hexagonal boron nitride hot pressed shapes

* Crucibles for melting glass and metals

* Break rings for horizontal continuous castings

* Compounds for high-temperature electric furnaces

* Structural parts for magnetohydrodynamic devices

* Dielectric for radar antennas and windows

* Insulators for low- and high-frequency equipment

* Insulators for plasma-jet furnaces, arc pulse generators and ion engines

* Holders, mounting plates, substrates and heat sinks in valve and transistor circuits

* Pump components, pipes and nozzles for handling liquid metals

* Protective tubes and insulating sleeves for thermocouples

* Protective sleeves for electrodes in automatic welding

* Wafers for boron-doping of semiconductors

* Moulds for hot pressing of ceramics like $\mathrm{B}_{6} \mathrm{O}$ or

$\mathrm{B}_{6.5} \mathrm{C}$

* Neutron absorbers and shields for nuclear reactors

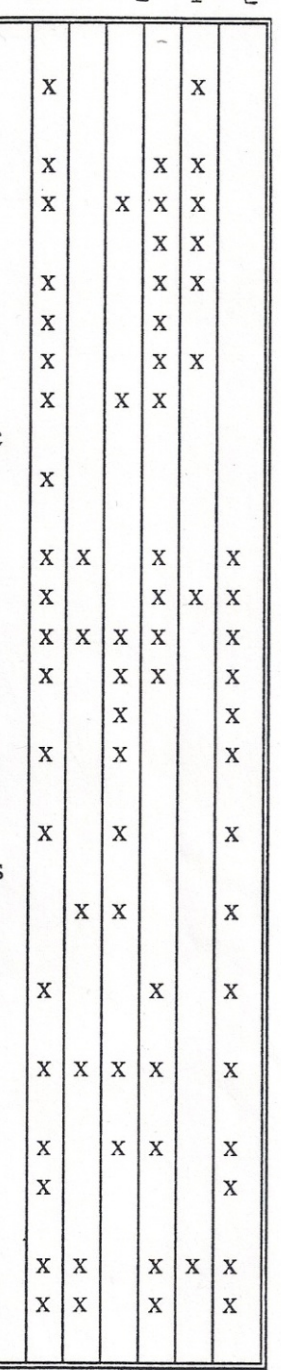

Figure 2. The applications of boron nitride [1].

\subsection{Insulators for high temperature furnaces}

The heating elements of resistance-heated electric furnaces, like graphite, molybdenum or tungsten-tube high temperature furnaces, require fixing devices made from ceramic insulating materials [5]. 

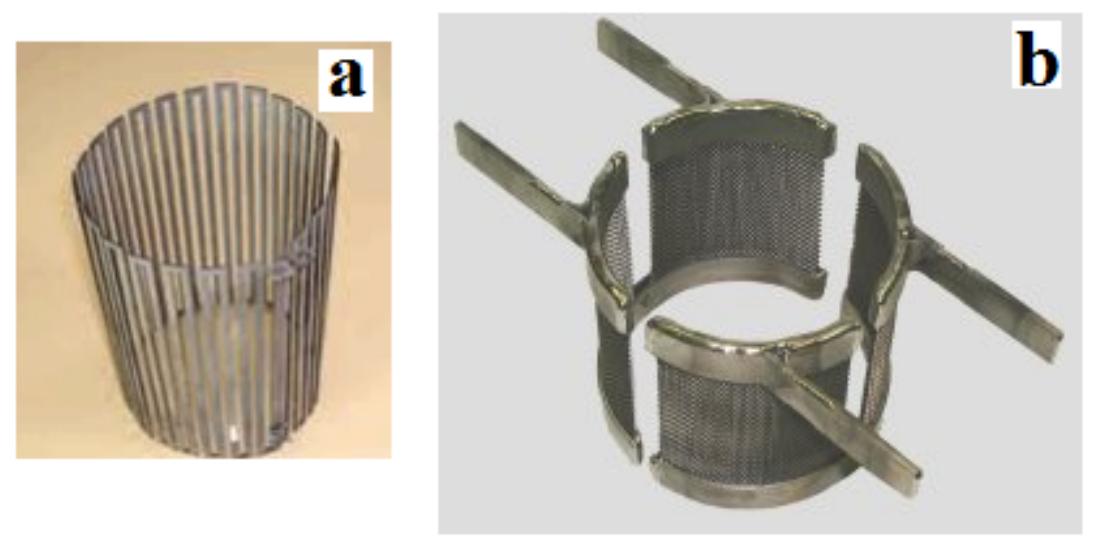

Figure 3. a.tunsten heater [6] and b. tunsten/molybdenum weave and mesh furnace elements [7].

Today due to frequent breakdown of oxide ceramic insulators at temperatures higher than $2000^{\circ} \mathrm{C}$, hexagonal boron nitride insulators are almost exclusively in use [5].
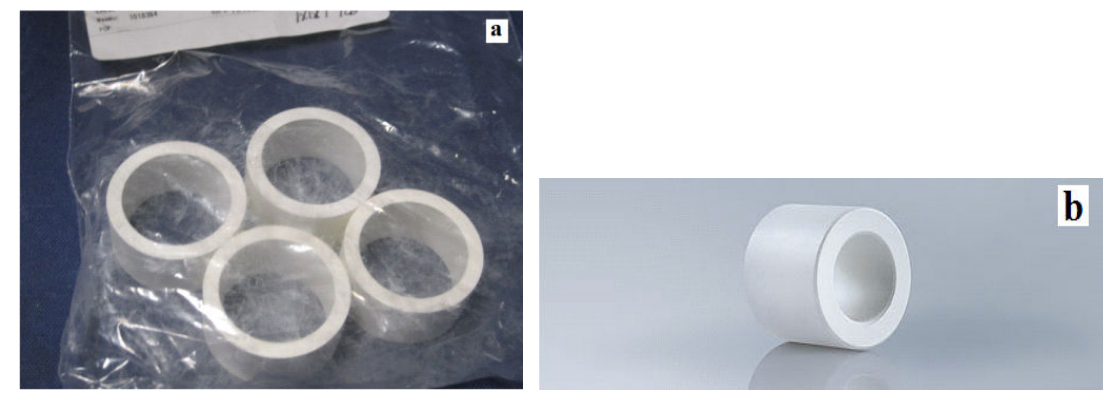

Figure 4. a. boron nitride insulator [8], b.insulator for furnace construction [9].

Therefore the $\mathrm{BN}$ material should contain only minimum amounts of boric oxide since $\mathrm{B}_{2} \mathrm{O}_{3}$ exudes at high temperatures and finally forms a conductive surface layer [5].

\subsection{Protective tubes and insulating sleeves for thermocouples}

The high temperature refractoriness, high thermal conductivity and high electrical resisivity of dense hexagonal boron nitride are utilized as thermocouple protection tubes and insulating sleeves. Preferably for the new $\mathrm{B}_{4} \mathrm{C} / \mathrm{C}$ thermocouple which can be used up to $2200^{\circ} \mathrm{C}$, hexagonal boron nitride sleeves are used. The $\mathrm{B}_{4} \mathrm{C} / \mathrm{C}$ couple consists of a graphite tube and a $\mathrm{B}_{4} \mathrm{C}$ rod connected to ecah other by a conical fitting. This end is exposed to the heated area. Along its entire length the $\mathrm{B}_{4} \mathrm{C}$ rod is insulated from the graphite tube by a hexagonal boron nitride sleeve of segmented construction [5]. 

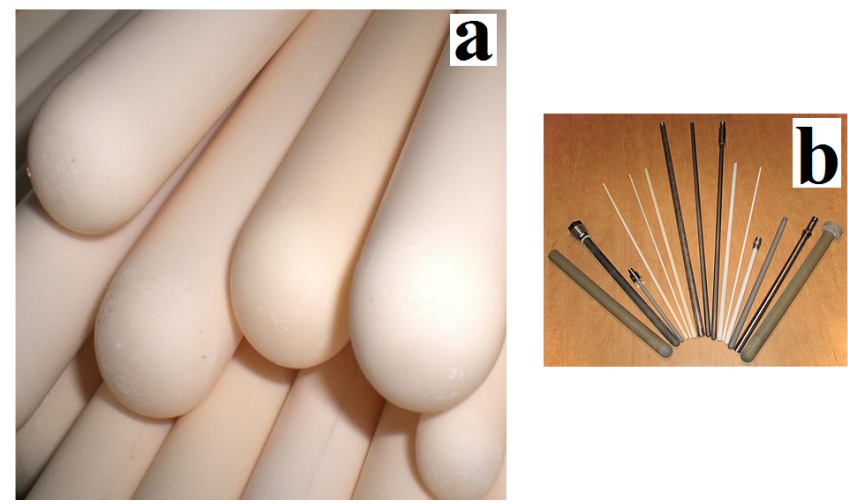

Figure 5. a. thermocuple protection tubes [10], b. tubes made of several materials [11].
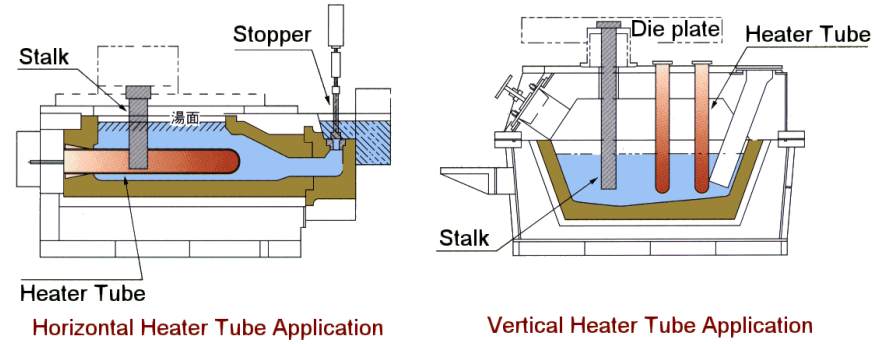

Vertical Heater Tube Application

Figure 6. Heater protection tubes [12].

Typical fields of application are sintering furnaces, hot presses and hot isostatic pressing equipment working in the temperature range $1800-2200^{\circ} \mathrm{C}$. The thermocouple should only be used in a rare gas atmosphere or under vacuum. If the inert gas used contains oxidizing gases or nitrogen, reaction with the graphite tube and the $\mathrm{B}_{4} \mathrm{C}$ rod will occurr, which can strongly influence the life of the thermocouple [5].

\subsection{Break rings for horizontal continous casting of steel}

The high chemical and thermal stability combined with the non-wetting property makes hexagonal boron nitride a useful crucible and structural material in metallurgical applications. For horizontal continuous casting of non-ferrous metals, graphite can be used as mould. However, the higher melting temperatures of steel alloys and their aggressiveness towads graphite and other conventional refractory metarials results in the need for special materials at the point of connection between tundish and the mould. This connection consists of a casting nozzle made of a high quality refractory such as zirconium oxide and a break ring made of boron nitride or a BN-composite ceramic. The sizes and shapes of the break rings and geometry are generally dependent on the type of equipment and type of steel (high or low alloy steels) [5]. 


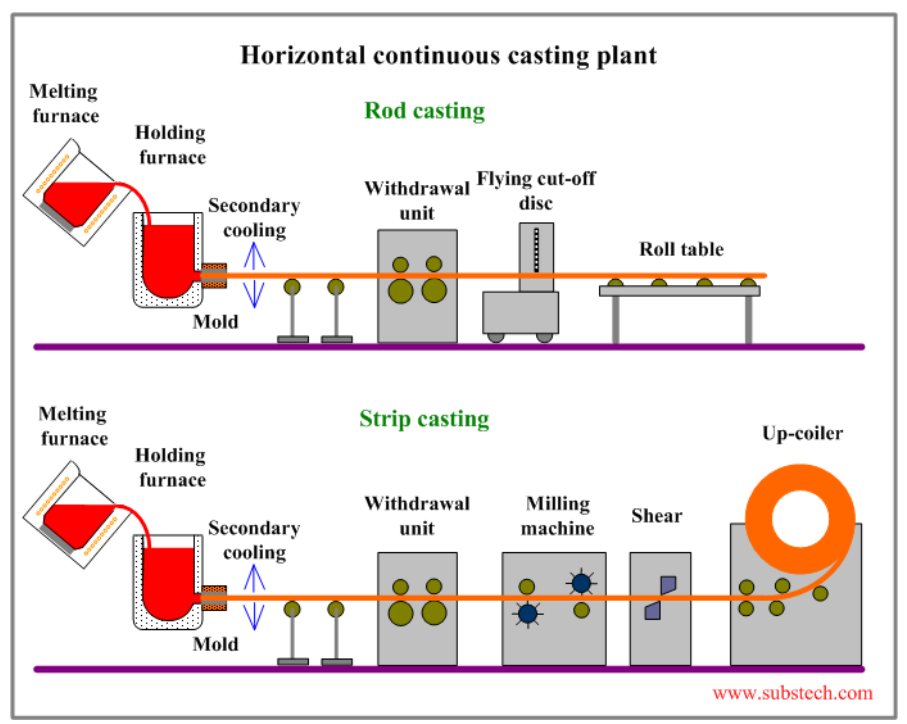

Figure 7. Horizontal continous casting [13].
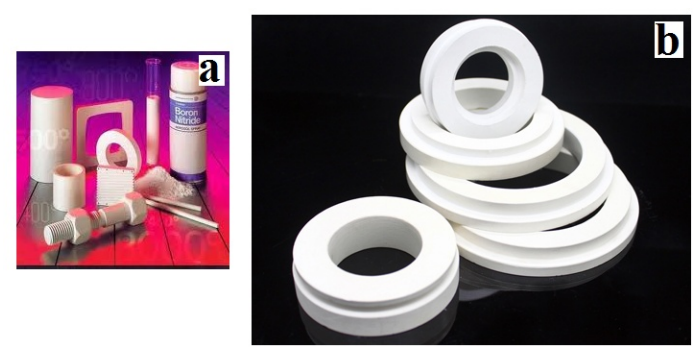

Figure 8. a. h-BN parts including break rings [14], b. Boron Nitride Horizontal Continuous Casting Split Rings [15].

Cross-sections of 50-250 mm diameters are now in use. The break ring determines the zone in which the liquid steel forms a solid. In addition the break ring must act as a seal or gasket with the tundish and the mould itself. The reaction of the ceramic boron nitride ring with steel alloying agents such as nickel, chromium, tungsten, manganese, sulphur etc. can cause breakdown of the BN material during service life. Therefore particular emphasis has been placed upon $\mathrm{BN}$-composite materials to prevent this corrosive attack. Until now the least wear of all BN composites has been shown by the SC-BN material ; today 100-200 tonnes of steel per break ring in low alloy steel and 40-100 tonnes in high alloy steel can be cast using this new SC-BN material. Other BN metallurgical processing applications include crucibles for molten sodium carbonate at $900-1150^{\circ} \mathrm{C}$ and crucibles for production of single crystals in high vacuum (Al-Li and $\mathrm{Cu}-\mathrm{Ti}$ alloys) [5]. 


\subsection{Pyrolytic boron nitride crucibles}

A low-volume but high-value use for pyrolytic BN is for crucibles for growing GaAs single crystals by the liquid encapsulation technique [5].

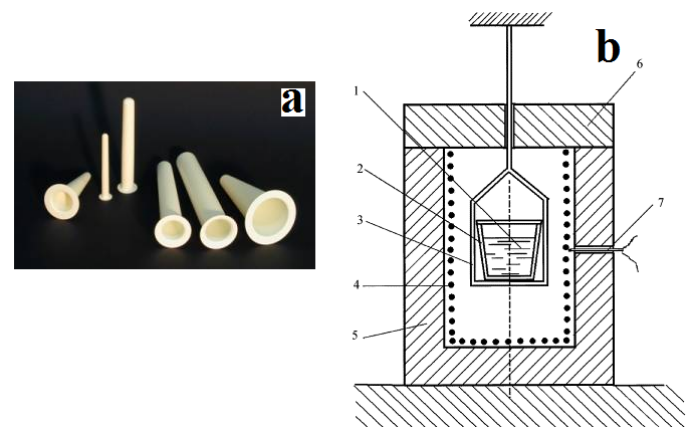

Figure 9. a. Pyrolytic boron nitride crucibles [16], b. thin-wall PBN crucible [17].

\section{The hot-pressing and the microstructural properties of hexagonal boron nitride}

\subsection{Experimental procedure}

The starting powders used for preparing h-BN ceramics were BN (C grade, H.C.Starck, Germany). Powder characterization was carried out on starting h-BN powders. The powder composition was confirmed by chemical analysis. Particle size, surface area, tap density and powder morphology of the h-BN powders were determined by Malvern Laser Particle Analyzer, BET analysis, Quantachrome pycnometer and SEM analysis, respectively. Hexagonal boron nitride (h-BN) based ceramics were fabricated by reactive hot-pressing in a graphite die with $\mathrm{BN}$ coating at $1900^{\circ} \mathrm{C}$ under a pressure of $50 \mathrm{MPa}$ for $60 \mathrm{~min}$. with $\mathrm{B}_{2} \mathrm{O}_{3}$ as sintering additive in a nitrogen atmosphere. The obtained products had dimensions of $80 \mathrm{~mm} \times 80 \mathrm{~mm}$ x $10 \mathrm{~mm}$. Hot-pressed ceramics were cut into cube-shaped samples with dimensions approximately $10 \mathrm{~mm} \times 10 \mathrm{~mm} \times 10 \mathrm{~mm}$. using a precision diamond saw. The sintered densities were determined on cube-shaped samples by Archimedes' method. The microstructural properties of h-BN powder and hot-pressed surfaces were evaluated by SEM-EDS analysis. Prior to SEM analysis, agglomerated BN particles were dispersed in acetone and adhered on a carbon tape and then coated with carbon. For the sintered bodies, the formation of the secondary phase was also investigated with particular interest on grain boundaries via SEM-EDS analysis [18].

\subsection{Results and discussion}

Powder morphology of the h-BN powders was shown in SEM images. Unlike the typical platelet shaped h-BN powder particles, near-spherical shaped particles can be observed in the 
SEM images in Fig.10. These spherical particles could be explained as molten $\mathrm{B}_{2} \mathrm{O}_{3}$ particles that were not converted to BN during synthesis [18].
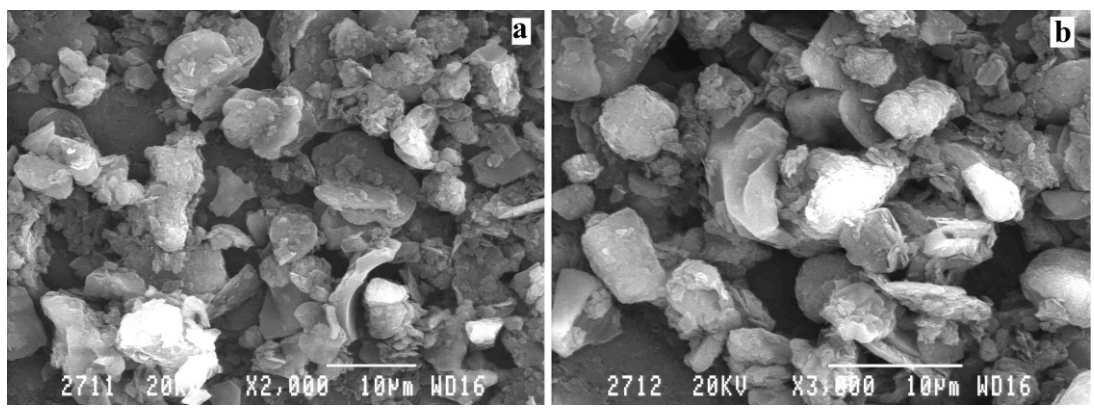

Figure 10. h-BN powder SEM micrograph (secondary-electron image) at (a)2000x and (b)3000x [18].

An average value of $92 \%$ of the theoretical density was achieved by the hot pressing process. Apparent density values of $81-96 \%$ of the theoretical density were obtained in related literature studies carried out on $\mathrm{h}-\mathrm{BN}$ based ceramics formed by hot pressing depending on the process temperature and the composition [18].

Microstructural observations by SEM revealed an orientation of the c-axis of the crystal, parallel to the hot pressing direction as shown in Fig. 11. SEM observations indicated a fine platelet evolution in the hexagonal boron nitride grains. It is known that regardless of the type of sintering aids used, products manufactured from hexagonal boron nitride powder by hotpressing exhibit a directional grain growth and an anisotropic microstructure due to the biaxial application of pressure at a high temperature so that the properties of the articles are directiondependent. The degree of anisotropy increases as higher degrees of densification are achieved. In other words, a high degree of orientation of the hexagonal boron nitride grains leads to mechanical anisotropy. Densification via hot-pressing occurs by three consecutive mechanisms: re-arrangement of the powders, removal of open porosity by plastic deformation and elimination of closed porosity by bulk diffusion processes [18].

In the re-arrangement process, as the low melting compound $\left(550^{\circ} \mathrm{C}\right), \mathrm{B}_{2} \mathrm{O}_{3}$, as a glass networkforming oxide, forms an intergranular liquid phase at a relatively low temperature during the sintering process. Thus promotes the orientation of the hexagonal boron nitride grains. Therefore the presence of a limited content of boron oxide is anticipated to enhance the densification process and grain orientation regarding the high purity h-BN grades. As can be seen from Fig.11, hexagonal boron nitride grains aligned perpendicular to the hot pressing direction and platy grains had an average diameter of $5 \mu \mathrm{m}$ and a thickness of $1 \mu \mathrm{m}$. However, a high degree of orientation was not observed therefore not all the grains in the microstructure aligned towards the hot-pressing direction. This particular microstructural feature could be expected to reduce the strong anisotropy of the hot-pressed bodies. The low degreee of orientation prevents efficient packing and lowers density besides basal planes near parallel to the hot pressing direction act as flaws on the microstructural scale and decreases flexure 
strength. Thus orientation and densification characteristics are important from the mechanical point of view [18].
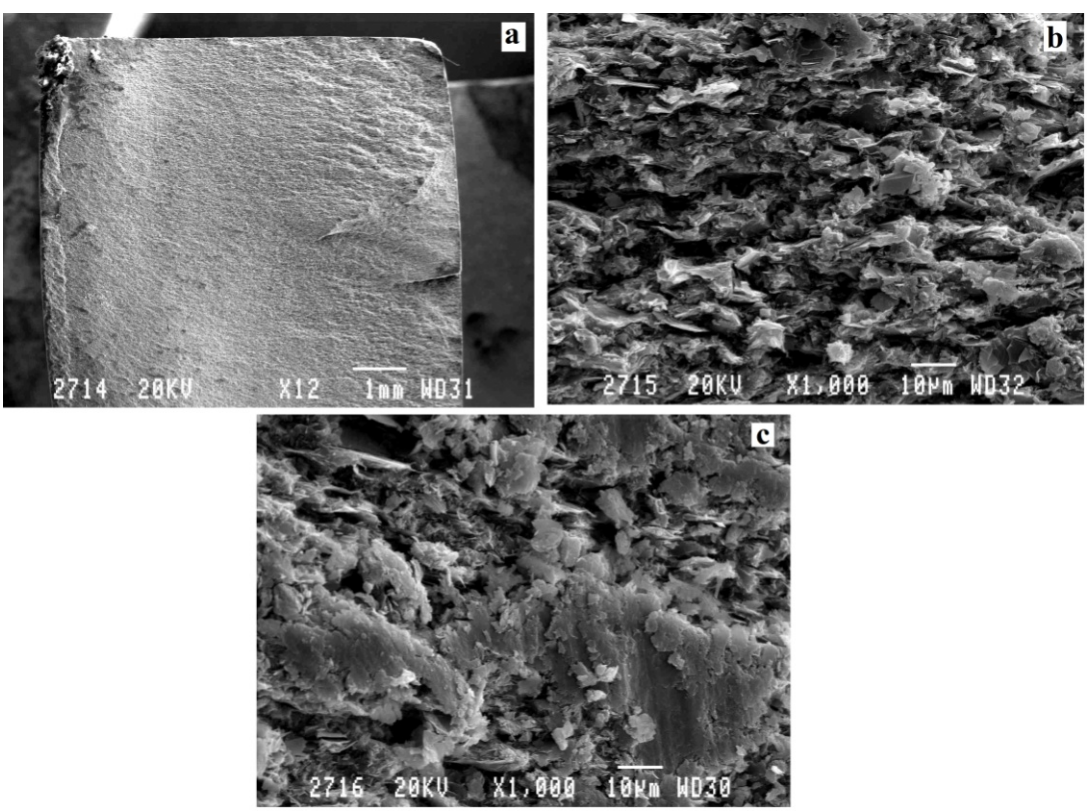

Figure 11. Hot-pressed hexagonal boron nitride microstructure (a) Low magnification, (b) high magnification and (c) plastic deformation at the fracture surface [18].

The hot-pressing operation, which involves the hexagonal boron nitride grains containing boron oxide, is not just a physical process. The trapped-in h-BN between the pressing rams and the inner wall of the matrix undergoes a decomposition reaction with the thermally released water as follows:

$\mathrm{nBN}+3 \mathrm{H}_{2} \mathrm{O}=\mathrm{B}_{2} \mathrm{O}_{3}+(3 \mathrm{n}-2) \mathrm{BN}+3 \mathrm{H}_{2}+\mathrm{N}_{2}$

Regarding the equation above, one can expect that a higher oxygen content will be in the hotpressed body than in the starting h-BN powder since the yield of boron oxide in the reaction product is reversally proportional to the crystallite size. Above explanation was confirmed by XRD analysis results in Fig.12. Thus in XRD patterns a single phase was observed. Despite the presence of boron oxide in the microstructure, no sign of $\mathrm{B}_{2} \mathrm{O}_{3}$ was observed due to the amorphous structure.The results of the SEM/EDS analysis demonstrated that nitrogen is distributed throughout the cross section, while oxygen is localized in the grain boundary structures. SEM images indicated that a glassy amorphous phase is present in the grain boundaries. $\mathrm{B}$ and $\mathrm{O}$ in the grain boundaries suggest an amorphous oxide phase as confirmed by XRD analysis, which denotes a preferential oxidation [18]. 


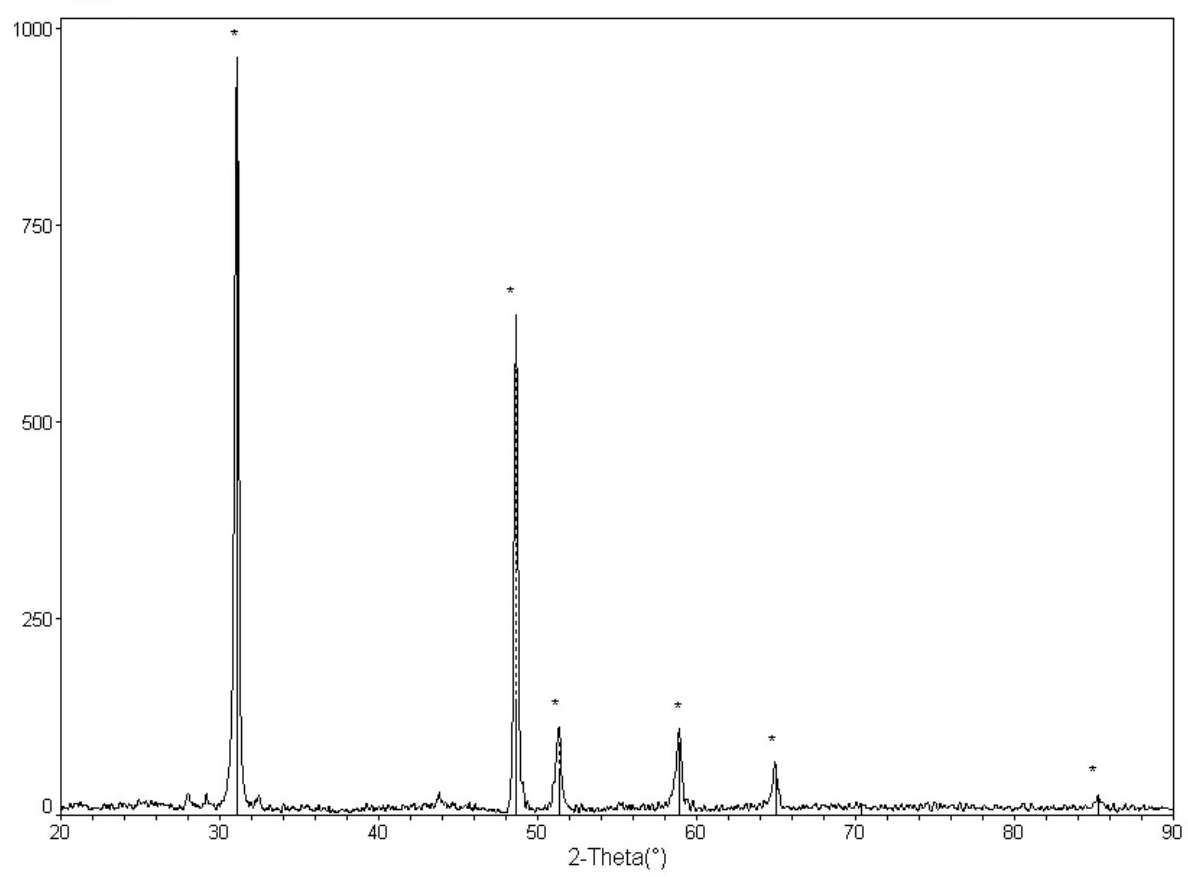

Figure 12. XRD pattern of hot-pressed h-BN ceramics [18].

\section{The hot-pressing and the mechanical properties of hexagonal boron nitride}

\subsection{Experimental procedure}

The overall mechanical characterization of hot-pressed hexagonal boron nitride (h-BN) based ceramics was performed. Hardness of the h-BN ceramics was tested on the polished samples by means of Vickers hardness tester, the applied load was $0.3 \mathrm{~kg}$ and the duration was 20 seconds. The indentation cycle was repeated at 15 points in each specimen with a step of $0.5 \mathrm{~mm}$ from one point of indentation to another. The length of the reciprocal diagonals of the indentation made by Vickers diamond pyramidal indenter tool was determined using optical microscope. The measurements were performed for parallel and perpendicular surfaces and then an average hardness value (HV) was determined for both surfaces. Specimens for strength measurements were cut from the hot-pressed plates into small rectangular blocks. The tensile surfaces of the samples were ground with silicon carbide papers and then polished with diamond paste along the longitudinal direction of the specimens until a scratch-free surface was 
obtained. The four edges of the specimens were chamfered in order to minimize the stress concentration induced by the machining flaw. The strength tests were carried out on Instron universal materials testing machine. Flexure strength (MOR) measurements were performed by three-point bending tests (test bars $4 \mathrm{~mm} \times 3 \mathrm{~mm} \times 45$ $\mathrm{mm}$ ) with a span of $40 \mathrm{~mm}$ and a crosshead speed of $0.5 \mathrm{~mm} / \mathrm{min}$. according to ASTM C1161-94. Five samples were tested for parallel and perpendicular surfaces and two average flexure strength values were obtained [19].

Fracture toughness (KIC) was evaluated by a single edge-V-notched beam (SEVNB) test, the dimensions of testing bars were $3 \mathrm{~mm} \times 4 \mathrm{~mm} \times 45 \mathrm{~mm}$ with a notch of $0.3 \mathrm{~mm}$ width and 2 $\mathrm{mm}$ depth. The fracture toughness tests were performed by four-point bending tests with a span of $40 \mathrm{~mm}$. according to ASTM C1421. Five specimens were tested for each experimental condition. Prior to the testing, each specimen was mechanically polished to a mirror finish from both sides and five specimens were mounted parallel and side by side with their compression surface down on a plate and a straight notch to a depth of about $0.5 \mathrm{~mm}$ was tapered at the center of each specimen's tensile surface with a diamond wheel and then a second deeper notch was polished with a razor blade sprinkled with diamond paste as shown in Fig. 1. Following the four-point bending tests, the fracture toughness value, KIC was computed using the equation as follows:

$\mathrm{KIC}=\mathrm{F} / \mathrm{B} \sqrt{ } \mathrm{W} . \mathrm{S} 1-\mathrm{S} 2 / \mathrm{W} .3 \sqrt{ } \alpha / 2(1-\alpha) 1.5 . \mathrm{Y}^{*}$

where, F, Sx, a, B are the fracture load, span, notch depth, specimen width, respectively and $\mathrm{W}, \alpha, \mathrm{Y}^{*}$ are specimen height, a/W, stress intensity shape factor, respectively. Finally the fracture characteristics of hot-pressed h-BN ceramics was investigated by analyzing fracture surfaces after bending tests using scanning electron microscope (SEM, JEOL JSMT330 at $20 \mathrm{kV}$ ) [19].

\subsection{Results and discussion}

Several studies on hot-pressed boron nitride based ceramics denote a range of 15-285 Vickers hardness values for various compositions. On the other hand, particular work on hexagonal boron nitride ceramics point out a range of $0.15-0.24 \mathrm{GPa}$, which indicates that our results are agreeable within error. The average hardness value obtained, ranged from $\mathrm{HV}=0 ., 20 \mathrm{GPa}$ to $\mathrm{HV}=0.25 \mathrm{GPa}$, which was higher in the surfaces parallel to the hot pressing direction due to the perpendicular alignment of the basal planes of the h-BN platelets to the hot pressing direction.

The results of the three-point bending tests carried out on surfaces parallel to the hot pressing direction indicated a relatively low average flexure strength (MOR) value of $0.14 \mathrm{GPa}$, which is in agreement with several studies on hexagonal boron nitride based composites confirming similar results regarding the flexure strength. A high degree of orientation of the hexagonal boron nitride grains was shown to lead to mechanical anisotropy. The flexure strength was found to be higher for the basal planes of the hexagonal boron nitride grains, which contain a covalent bonding of boron and nitrogen atoms. The average flexure strength value for the perpendicular direction was determined to be $0.17 \mathrm{GPa}$. 
For the fracture toughness evaluation, a SEVNB test was conducted, where a linear stress profile occurs with tensile stresses below the neutral axis of the pre-cracked specimen and compressive stresses. This particular stress profile ensures the steady propagation of the crack initiated from the sharp notch root depending on the load. It is known that the anisotropy in the microstructure has also an influence on the fracture toughness. The cracks formed on the surface have a tendency to deviate in the direction of platelets due to the orientation and in some cases could not propagate at all. However, for the case that the direction of the crack propagation is not perpendicular to the basal planes of the platy grains, fracture toughness is not affected by the orientation of the grains. The average fracture toughness value was determined to be $2.6 \mathrm{MPa} . \mathrm{m} 1 / 2$. A single KIC value was obtained since a slight variation of the fracture toughness was observed with the orientation of h-BN due to aforesaid causes [19].

Finally the fracture characteristics of hot-pressed h-BN ceramics was investigated by analyzing fracture surfaces after bending tests using SEM using ASTM C1322. In Fig. 13, crack path of the fractured specimens after three-point bending test was indicated. No crack deflection was observed for each of the five bending tests, which is a sign of the high degree of grain orientation. Instead, crack followed a more straight path through the thickness of the specimen proving a low degree of grain orientation. The two sides of the fracture surface fit together very well after failure [19].

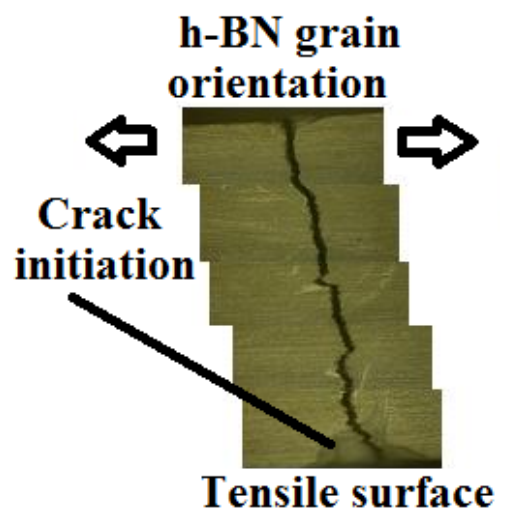

Figure 13. Crack path of the fractured specimens after three-point bending test [19].

The fracture halves were mounted back to back in order to reveal the crack path. Fig.11 shows the relatively flat fracture surface of the specimens. The stripped region at low magnification indicates the crack initiation pattern perpendicular to the applied stress on the fracture surfaces of three-point bending rods as shown in Fig.11.a. The crack formed at the maximum stress region, where typically occurs some plastic flow, easily propagates to reach the smooth surface of the specimen. Fig.11, shows a completely brittle type of fracture exhibiting small plastic deformation before failure. Thus the microstructural observations of h-BN grains indicated completely brittle fracture with intergranular voids and microcracks inside the individual 
grains revealing a mixed mode of fracture. A combination of a typical predominant transgranular fracture mechanism at room temperature and intergranular cracking due to the presence of grain boundary phase content was determined as a result of fracture tests [19].

\section{The hot-pressing and the thermal and mechanical properties of $h-B N /$ TiB2 composites}

\subsection{Experimental procedure}

The starting powders used in this study were: $\mathrm{TiB}_{2}$ powder (H. C. Starck), average size 0.7-2.0 $\mu \mathrm{m}$ and $\mathrm{h}-\mathrm{BN}$ powder (H.C.Starck). In order to examine the effect of composition on mechanical and thermal properties, 5 series of $\mathrm{TiB}_{2} / \mathrm{h}-\mathrm{BN}$ compositions were prepared in this study. The powder mixtures were ball-milled in a YSZ vial (MSE Mill) using ethanol as a solvent for $3 \mathrm{~h}$ and resulting slurry was then dried. The obtained powder mixtures were hot pressed in graphite dies at $1900{ }^{\circ} \mathrm{C}$ for $1 \mathrm{~h}$ under a pressure of $30 \mathrm{MPa}$ in vacuum to yield consolidated and sintered samples with dimensions of $40 \mathrm{~mm} \times 40 \mathrm{~mm} \times 40 \mathrm{~mm}$. The densities, $\rho$, of the hot pressed composite compacts were measured using Archimedes method with distilled water as medium. The theoretical densities of composites were calculated according to the rule of mixtures. Microstructure of the composites was observed by scanning electron microscopy (SEM-Hitachi). The grain size, $\mathrm{d}$, was determined by measuring the average linear intercept length, $\mathrm{d}_{\mathrm{m}}$, of the grains in SEM images of sintered BN ceramics [20].

The hardness values of the $\mathrm{h}-\mathrm{BN} / \mathrm{TiB}_{2}$ composites was measured using a $\mathrm{HMV}^{\mathrm{TM}}$ Shimadzu Micro hardness tester (made in Japan). The surface of samples were prepared by using a Struers $^{\mathrm{TM}}$ Tegrapol-15 polishing instrument to obtain the accurate hardness values of the composites and then the hardness tests were performed on the polished surface of the specimens by loading with a Vickers indenter for $10 \mathrm{~s}$ in ambient air at room temperature. The corresponding diagonals of the indentation were measured by using an optical microscope attached to the indenter. The indentation load of $490 \mathrm{mN}$ was used and five indentations were made for each measurement. In addition, $\mathrm{X}$-ray diffraction (XRD) (Bruker ${ }^{\mathrm{TM}} \mathrm{D} 8$ Advance) was used for crystalline phase identification of the composites. Moreover, to examine the effect of addition powders, thermal expansion measurement was done in argon (Ar) atmosphere and $10{ }^{\circ} \mathrm{C} / \mathrm{min}$. temperature by using Anter Unitherm ${ }^{\mathrm{TM}}$ Model 1181 Dilatometer instrument [20].

\subsection{Results and discussion}

The microstructural images of three different samples were given in Fig.14. Since c-axis of HPBN was aligned along hot-pressing direction, anisotropy could be anticipated in h-BN containing samples. As shown in Fig.14., basal plane of graphite-like plates (T0BN) was aligned perpendicular to hot-pressing direction. On the other hand, in B50T50 samples hexagonal grains did not indicate any sort of alignment despite hot-pressing process. The platelet thickness of HPBN sample (TOBN) was measured to be $1 \mu \mathrm{m}$ after sintering at for $60 \mathrm{~min}$. in vacuum atmosphere. The grain size obtained in the present study was nearly half of the 
densityof fully sintered $\mathrm{TiB}_{2}$ in the literature. The grain sizes of 5 to $100 \mu \mathrm{m}$ were reported for the $\mathrm{TiB}_{2}$ sample which had theoreticaldensity of $4.5 \mathrm{~g} . \mathrm{cm}^{-3}$. Since hot-pressing is a hot consolidation technique and stress-enhanced densification of powders, a higher density for HPBN (T0BN) was expected in comparison to those samples which contain lower amounts of BN, i.e B50T50. In the hot-pressing process, initially, compaction is by particle rearrangement and plastic flow (particle yielding at point contacts). As densification progresses, grain boundary and volume diffusion processes become controlling. Pressing before sintering as in pressureless sintering, reduces porosity and increases the dislocation population in powder. Higher disclocation density contributes to an initially faster sintering rate. However, in the present study direct hot-pressing was used and low density percentages were obtained. The microstructure of h-BN composition (TOBN) indicated a good agreement with literature microstructural features. The as-sintered microstructure consisted of hexagonal platelets with basal planes perpendicular to hot-pressing direction. However, as can be seen in Fig.14, the index of orientation preference or degree of orientation defined in the literature was low for our sample, TOBN [20].

Refining the microstructure of the starting material, i.e. ball-milling h-BN/TiB ${ }_{2}$ powder to a defective, nanocrystalline or even amorphous state, enhances the reactivity. On the other hand, small grain sizes aid densification. That is why for five samples, ball-milled starting powder was employed. The main impurity in boron nitride powder was boric oxide, which is hygroscopic and is converted to boric acid. Since boron-oxygen compounds act as sintering aids during consolidation processes, 6 wt. $\%$ of $\mathrm{B}_{2} \mathrm{O}_{3}$ enhanced sintering behaviour (poor sinterability of $\mathrm{h}-\mathrm{BN}$ ) in all boron nitride containing samples except $\mathrm{B} 0-\mathrm{TiB}_{2}$. Despite vertical die pressure of hot-pressing process at high temperatures, $\mathrm{B}_{2} \mathrm{O}_{3}$ also assisted sintering in HPBN. The amount of additives used for densification has a great effect on the chemical and physical properties of h-BN. h-BN powder utilized in the present study was a two phase system involving mixed powders of $\mathrm{BN}$ and low-melting boric oxide. Boric oxide provided for rapid transport and rapid sintering. That is why boric oxide content was kept constant for five different compositions. The resultant parts of five samples were easily machined with standard tools to bars for mechanical measurements [20].

\begin{tabular}{|c|c|c|c|c|c|}
\hline \multirow[t]{2}{*}{ Materials } & \multicolumn{2}{|c|}{$\begin{array}{l}\text { Compositions } \\
\text { \%Vol. }\end{array}$} & \multirow{2}{*}{$\begin{array}{l}\text { Theoretical density } \\
\qquad \mathrm{g} / \mathrm{cm}^{3}\end{array}$} & \multirow[t]{2}{*}{ True density $\mathrm{g} / \mathrm{cm}^{3}$} & \multirow{2}{*}{$\begin{array}{c}\text { Relative density } \\
\%\end{array}$} \\
\hline & h-BN & $\mathrm{TiB}_{2}$ & & & \\
\hline TO-BN & 100 & 0 & 2.30 & 1.582 & 68.78 \\
\hline B75T25 & 75 & 25 & 2.86 & 1.977 & 69.11 \\
\hline В50T50 & 50 & 50 & 3.41 & 2.406 & 70.57 \\
\hline B25T75 & 25 & 75 & 3.97 & 2.845 & 71.66 \\
\hline $\mathrm{BO}-\mathrm{TiB}_{2}$ & 0 & 100 & 4.52 & 3.248 & 71.86 \\
\hline
\end{tabular}

Table 1. Compositions, density and relative densities of the hot-pressed h-BN/TiB ${ }_{2}$ composites [20]. 

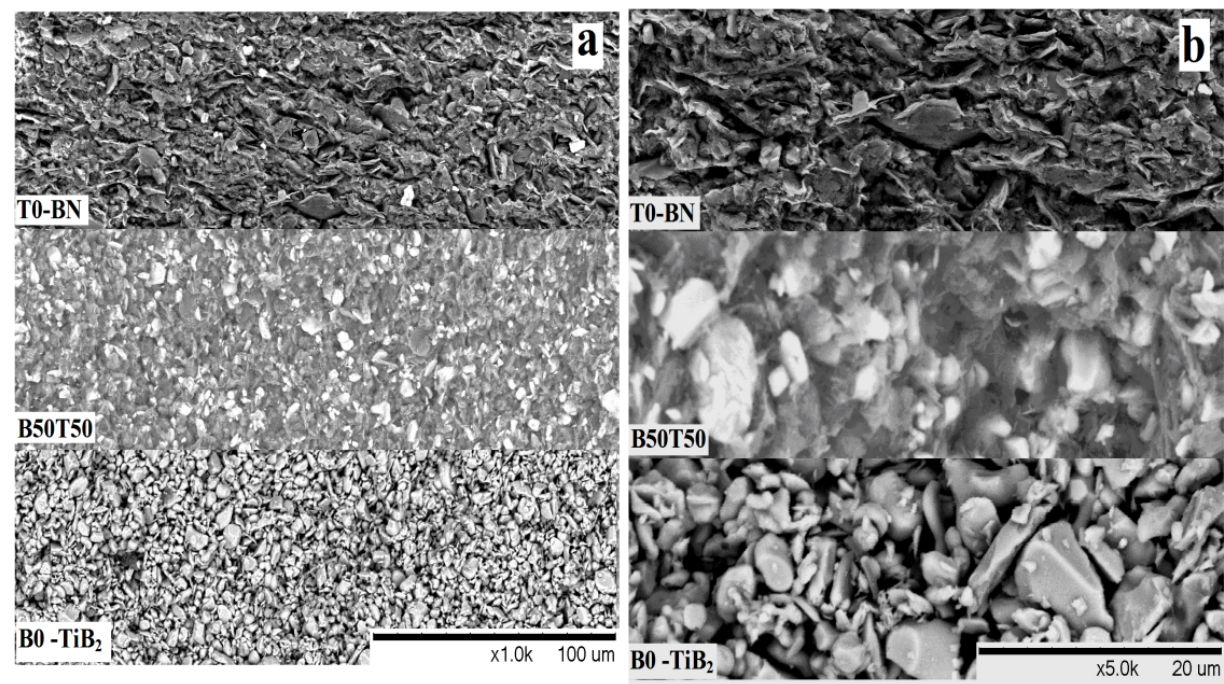

Figure 14. SEM images for 3 different samples at magnifications (a) $1 \mathrm{kx}$ and (b) 5kx. [20].

In general, micro-hardness is higher in the surfaces parallel to the hot pressing direction due to the perpendicular alignment of the basal planes of the h-BN platelets to the hot pressing direction. However, since h-BN content is lower than pure material in four of the samples, the anisotrophy in Vickers hardness was slight. The main difference between hot-pressed TOBN and B0$\mathrm{TiB}_{2}$ samples was the presence of high orientation of the hexagonal crystals and the grain growth, which was responsible for poor sinterability of pure h-BN sample. Due to the orientation of the crystals there could be different property data perpendicular and paralel to the pressing direction. B50T50 neither showed decrease in mechanical properties when measured at paralel to hot-pressing direction nor a dependence of microstructure on the direction [20].

In the Table 1, it is displayed that the densities of hot pressed samples decreased with the increase in the addition of boron nitride amount in the composition, the measured density for B25T75 is 2,845 g/cm $\mathrm{cm}^{3}$, for B50T50 is $2,406 \mathrm{~g} / \mathrm{cm}^{3}$ and for B75T25 is $1,977 \mathrm{~g} / \mathrm{cm}^{3}$ and T0-BN is $1.582 \mathrm{~g} / \mathrm{cm}^{3}$ which is in accordance with the theoretical density for boron nitride (BN). The

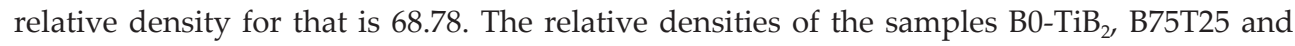
B50T50 are $71.86 \mathrm{~g} / \mathrm{cm}^{3}, 69.11 \mathrm{~g} / \mathrm{cm}^{3}$ and $70.57 \mathrm{~g} / \mathrm{cm}^{3}$ relatively, these values revealed that the measured densities of the samples much lower than the theoretical ones. This may be due to sintering conditions for $\mathrm{TiB}_{2}$ containing samples [20].

The X-ray diffraction patterns of the sintered samples were shown in Fig.15 XRD analysis of the as-sintered samples revealed that main phases are titanium diboride $\left(\mathrm{TiB}_{2}\right.$, PDF card No. 35-0741) and boron nitride (BN, PDF card No. 34-0421). According to the X-ray patterns, in the composition as the ratio of boron nitride $(\mathrm{BN})$ powder increased the peaks of $\mathrm{TiB}_{2}$ phase gradually decrease while the peaks belong to the boron nitride $(\mathrm{BN})$ phase getting stronger. The strongest peak for $\mathrm{TiB}_{2}$ phase is about $52^{\circ}$, for boron nitride (BN) which is around $31^{\circ}$ [20]. 

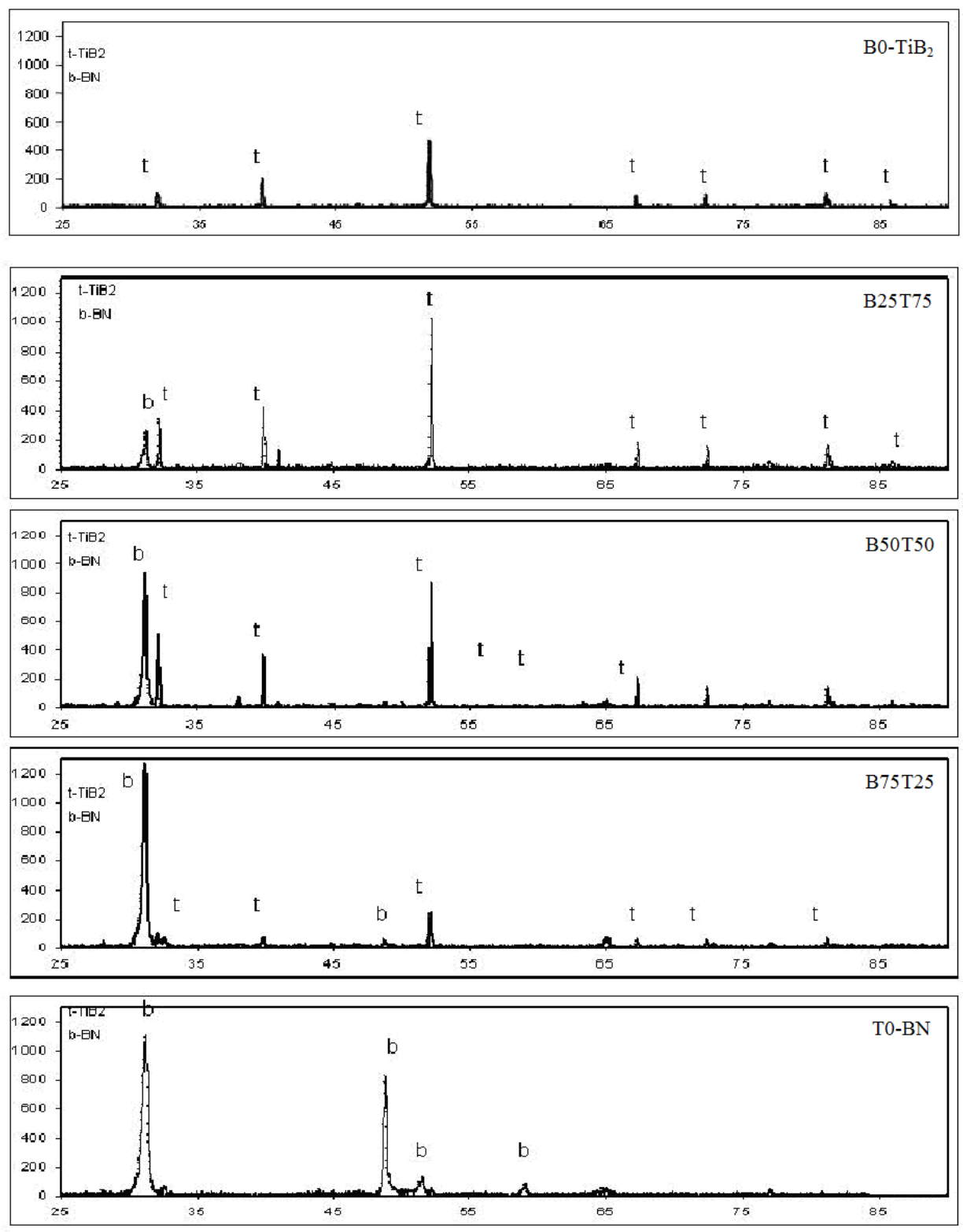

Figure 15. X-ray diffraction patterns of titanium diboride(BO-TiB 2 ) boron nitride(T0-BN), B25T75, B50T50 and B75T25 (t, titanium diboride; b, boron nitride) [20]. 
As expected, the content of $\mathrm{TiB}_{2}$ increased, Vickers micro-hardness increased. The average $\mathrm{Hv}$ value of h-BN was measured to be $75 \mathrm{~kg} / \mathrm{mm}^{2}$, which is good agreement with our previous study. As $\mathrm{TiB}_{2}$ content was raised, micro-hardness increased gradually to $145 \mathrm{~kg} / \mathrm{mm}^{2}$ when measured for the sample which contain $25 \%$ of $\mathrm{TiB}_{2}$. The highest Vickers value was obtained for the sample which contain $100 \%$ of $\mathrm{TiB}_{2}$. In a study by Munro, mechanical and thermal properties of nearly dense ( $98 \%$ of relative density and $4.5 \mathrm{~g} . \mathrm{cm}^{-3}$ of theoretical density) polycrystalline $\mathrm{TiB}_{2}$ were examined [20].

The diversity of the processing conditions is a significant factor in the often widely varying property values reported in the literature for polycrystalline $\mathrm{TiB}_{2}$. Thus porosity greatly affected our Vickers hardness results. The cursory examination of the data for the Vickers hardness of $\mathrm{TiB}_{2}$ has no immediately perceptible dependence on either density or grain size. However, our Vickers hardness, i.e $100 \%$ of $\mathrm{TiB}_{2}$ (B0TiB ${ }_{2}$ composition) was significantly affected by relative density and grain size $(3-4 \mu \mathrm{m})$. The maximum Vickers hardness obtained for the present study in Fig.16, was that of B0T100 composition, which had a value of $450 \mathrm{~kg} . \mathrm{mm}^{-2}$. The higher values measured in the literature was the result of full densification of $\mathrm{TiB}_{2}$ [20].

In Fig.17 the coefficient of thermal expansion curves as a function of temperature of h-BN, B50T50 and $\mathrm{TiB}_{2}$ compositions are plotted. Hexagonal boron nitride is known to have low coefficient of thermal expansion, i.e high thermal shock resistance. The thermal expansion coefficients of hot-pressed h-BN in the literature were reported as $1.1 \times 10^{-6}$ and $8.4 \times 10^{-6} \mathrm{~K}^{-1}$ for perpendicular and parallel to hot-pressing directions, respectively. CTE of hot-isostatic pressed sample was measured to be $4.1 \times 10^{-6} \mathrm{~K}^{-1}$. In the samples studied, the lowest thermal expansion belonged to the pure h-BN composition, $\mathrm{T} 0-\mathrm{BN}$. $\mathrm{As} \mathrm{TiB}_{2}$ content was raised, thermal expansion increased gradually as can be seen in the B50T50 curve. The coefficient of thermal expansion measured for $100 \%$ of $\mathrm{TiB}_{2}$ (B0T100) in the present study (obtained at room temperature) well fitted with the literature data, which was $7.4 \times 10^{-6} \mathrm{~K}^{-1}$ [20].

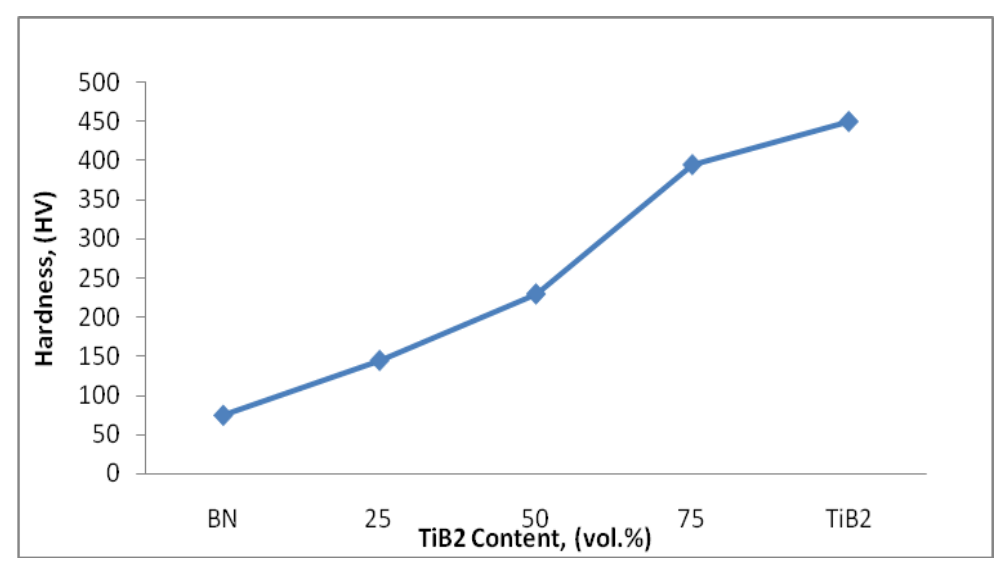

Figure 16. Plots of hardness of the hot-pressed h-BN/TiB ${ }_{2}$ composites as a function of $\mathrm{TiB}_{2}$ content [20]. 


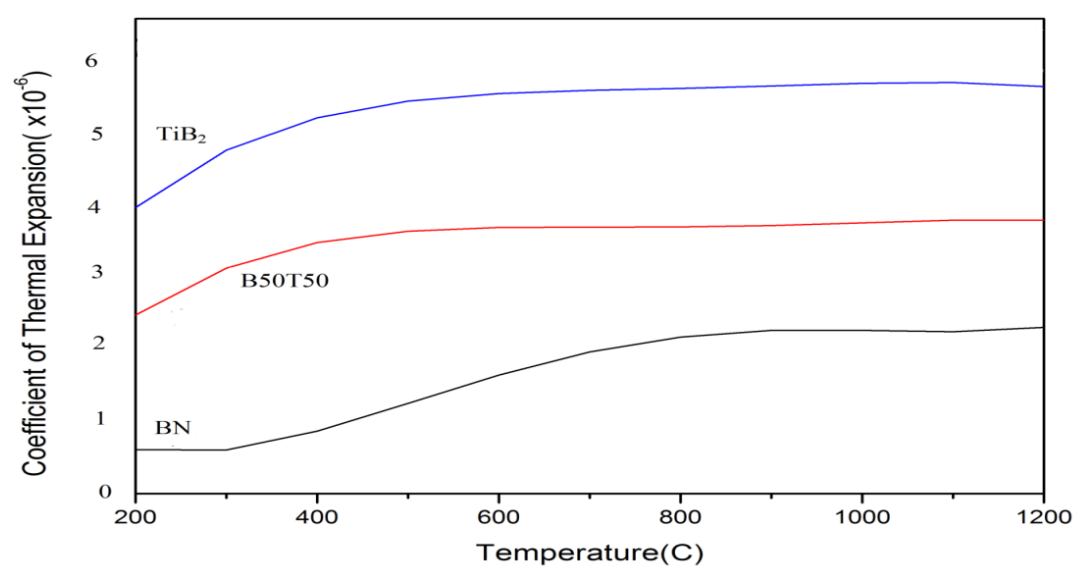

Figure 17. Plots of CTE of the hot-pressed h-BN/TiB ${ }_{2}$ composites as a function of temperature [20].

\section{Conclusion}

1. The first synthesis method of boron nitride is the direct nitridation of boron. In another method, boric acid or borax are heated in the presence of a nitrogen-containing compound such as ammonia or urea. Reacting alkali metal borides or alkaline earth metal borides with silicon and/or aluminum is another method. However, there is a tedious leaching step after the synthesis. The carbothermic decomposition of elemento-organic BN compounds can also yield boron nitride. The disadvantage is that all starting materials are oxygen and moisture sensitive. Pressure pyrolysis of borazine $\left(\mathrm{B}_{3} \mathrm{~N}_{3} \mathrm{H}_{6}\right)$ can also yield to $\mathrm{BN}$, namely in amorphous form.

2. Key boron nitride properties are high thermal conductivity, low thermal expansion, good thermal shock resistance, high electrical resistance, low dielectric constant and loss tangent, microwave transparency, non toxicity, easily machinability- non-abrasive and lubricious, chemical inertness, non-wetting by most molten metals.

3. Typical boron nitride uses are electronic parts (heat sinks, substrates, coil forms, prototypes), boron doping wafers in silicon semiconductor processing, vacuum melting crucibles, CVD crucibles, microcircuit packaging, sputtering targets, high precision sealing, brazing and metallizing fixtures, microwave tubes, horiziontal caster break rings, low friction seals, plasma arc insulators, high temperature furnace fixtures and supports.

4. In the first experimental study descibed in the present work, hexagonal boron nitride ceramics with boron oxide content as sintering additive were fabricated by the hot-pressing technique. The major microstructural features, grain orientation and densification characteristics of the hot-pressed ceramics were influenced by the presence of $\mathrm{B} 2 \mathrm{O} 3$. However, the enhancement of the sintering additive did not 
cause a strong grain orientation or microstructural anisotropy as shown by SEM analysis. Only a slight orientation of the h-BN crystals towards the hot-pressing direction was observed. Thus it is anticipated that the mechanical properties of the h-BN samples will not show serious variations with the hot-pressing direction due to the low degree of orientation.

5. The overall mechanical characterization of hot-pressed hexagonal boron nitride (hBN) based ceramics was conducted in the second experimental study. The effect of the anisotropy of hot-pressed h-BN based ceramics for various mechanical properties was determined. The mechanical characterization results were evaluated in terms of the orientation characteristics of hot-pressed ceramics. It was concluded that the hardness and the flexure strength properties in the hot-pressed h-BN ceramics are extremelydependent on the direction. Thus the average hardness and the flexure strength values are higher in the surfaces parallel to the hot-pressing direction. However, the measured fracture toughness (KIC) of the h-BN samples did not show serious variations with the hot-pressing direction. In addition, fracture characteristic of the hexagonal $\mathrm{BN}$ grains is determined to be completely brittle exhibiting a mixed mode of fracture. Crack path evaluations after the fracture tests indicated that no crack deflection occurred through the thickness of the specimen. Instead, the crack followed a straight path, demonstrating a low degree of grain orientation following the hot-pressing process.

6. In the final experimental study, the mechanical characterization of four hexagonal boron nitride containing and one titanium diboride samples, produced by hot pressing was conducted. It was concluded that the hardness and the fracture surface in the five samples were dependent on the h-BN content. On the other hand, fracture characteristic of the samples was brittle. There were both transgranular and intergranular cracks in the microstructures. After 3-point bending test, the crack followed a straight path, demonstrating a low degree of grain orientation. It was concluded that TiB2 content increased the thermal expansion property of hBN ceramics.

\section{Acknowledgements}

This chapter would not have been possible without the guidance and the help of several individuals who in one way or another contributed and extended their valuable assistance in the preparation and completion of this study. First and foremost, my utmost gratitude to Professor Dr. A. Okan Addemir, my Ph.D thesis advisor, who gave me the idea of working on the interesting subject of hexagonal boron nitride. I would like to thank to Assistant Professor Dr. Tahsin Boyraz whose sincerity and encouragement I will never forget. Dr. Boyraz has been my inspiration as I hurdle all the obstacles in the completion this research work. Dr. Gülten Sadullahoğlu, has been a great friend and support for me during my post doctoral studies. Finally many thanks for my parents for their silent encouragement. But most of all a loving thank you to my sister, Deniz, for her understanding and gracious support. 


\section{Author details}

\section{Burcu Ertuğ}

Address all correspondence to: burcuertug@gmail.com

Istanbul Technical University, Department of Metallurgical and Materials Engineering, Maslak, Istanbul, Turkey

\section{References}

[1] S. Alkoy, Crystallization behaviour and characterization of turbostratic boron nitride, July 1994, Istanbul Technical University, Graduate School Of Science, Engineering and Technology.

[2] Ş. Pekin, The reaction rate controlling steps and turbostratic hexagonal structure transition in hBN synthesis, July 1992, Istanbul Technical University, Graduate School Of Science, Engineering and Technology.

[3] Development and application of high-purity hexagonal boron nitride (h-BN) powder, Kawasaki Steel Technical Report No:28, June 1993, 17-25.

[4] http://accuratus.com/boron.html

[5] A.Lipp, K.A. Schwetz and K. Hunold, Hexagonal boron nitride: fabrication, properties and applications, Journal of the European Ceramic Society, 5, 1989, 3-9.

[6] http://htemps.en.made-in-china.com/

[7] http://www.oxy-gon.com/

[8] http://buy.capitolareatechnology.com/

[9] http://www.esk.com/en.html

[10] http://www.diytrade.com/china/main.html

[11] http://www.rdccontrol.com/en/index.html

[12] http://www.crystec.com/tkralue.htm

[13] http://www.substech.com/dokuwiki/doku.php?id=main_page

[14] http://www.trademart.in/

[15] http://en.pensc.com/index.html

[16] http://www.junsun.url.tw/e-p2-1-1.html

[17] http://www.sciencedirect.com/science/article/pii/S0022024898006204 
[18] B. Ertuğ, T. Boyraz, A.O. Addemir, Microstructural Aspects Of The Hot Pressed Hexagonal Boron Nitride Ceramics With Limited Content Of Boron Oxide, Materials Science Forum, 554, 197-200, 2007.

[19] B.Ertuğ, T. Boyraz, A.O. Addemir, An Investigation Of The Mechanical Properties And Fracture Characteristic Of Hot-Pressed Boron Nitride Ceramics, Materials Science Forum, 554, 201-205, 2007.

[20] A.C. Akarsu, H. Gökçe, T. Boyraz, B.Ertuğ, A.O. Addemir, M.L. Öveçoğlu, The Characterization of The Mechanical And Thermal Properties Of Hot-Pressed Hexagonal Boron Nitride-Titanium Diboride Composites, 3rd International Symposium on SiAlONs and Non-Oxides, June 1-4, 2010. 
